\title{
A Biosemiotic Perspective on Reward-Based Animal Training Techniques
}

\author{
Amelia Lewis ${ }^{1}$ \\ Received: 16 April 2021 / Accepted: 19 August 2021/ Published online: 3 September 2021 \\ (C) The Author(s) 2021
}

\begin{abstract}
In this paper, I examine the way humans interact with domestic companion animals, with a focus on 'positive reward-based training' methods, particularly for dogs. From a biosemiotic perspective, I discuss the role of animal training in today's society and examine what binary reward- based reinforcement schedules communicate, semiotically. I also examine the extent to which reward-based training methods promote better welfare, when compared to the more traditional methods which rely on aversive stimuli and punishment, if and when they are relied upon excessively. I conclude that when used as the primary means of communication, they have the potential to be detrimental to animal welfare, because the underlying social signal is control and resource dominance. As an alternative view to behaviourist-based learning theory and conditioning, I outline how enactivist theories of cognition support a semiotic approach to interspecific human-animal communication. I therefore propose a move toward a dynamic semiosis and mutual understanding based upon Peirce's phenomenology, resulting in a more balanced merging of Umwelten. The aim is to create rich and more complex semiospheres around humans and domestic animals, which allow for individual agency and autonomy.
\end{abstract}

Keywords Animal training · Umwelt · Peirce's phenomenology $\cdot$ Human-animal interaction: communication · Contra-freeloading

\section{Introduction}

Across cultures, human societies keep domesticated animals as companions. The domestication of dogs, for example, can be traced back to a period over 15, 000 years ago, yet theories as to how this process occurred are speculative. Most commonly promote the idea of a mutualistic interaction, whereby humans and wolves co-operated

Amelia Lewis

Alewis08@qub.ac.uk

1 School of Biological Sciences, Queen's University, Belfast, Belfast, UK 
during foraging and hunting, the defense of territory, and in social companionship (Vilà et al., 1999; Morey, 1994). However, for this to have happened, individuals of the two species must have shared a part of their Umwelten, creating a Total Umwelt (Lewis 2020a) which paved the way for a semiosphere to form. Significantly, though, the ancestors of the domestic dog (various wolf species), are large predators capable of harming or even killing a human, rendering subjugation by humans very difficult. Thus, it is a reasonable assumption that humans and canids were able to communicate, without the requirement for formal training, or indeed any kind of ritualized interaction. Original associations must have taken place entirely in the semiome, a concept described by Hoffmeyer (2014a), despite the marked sensory and cognitive differences between species. Indeed, how else would one form a co-operative alliance with another (potentially dangerous) individual, on the basis of benefits such as food acquisition, without understanding, on some level, that the food is willingly offered in return for reciprocal benefits? Conditioning alone does not account for the initiation of social relationships between the species, and serendipity does not account for a predator willingly cooperating with its prey (or vice versa) without some degree of mutual understanding. Indeed, even today, there are recommended safety measures, and employment of protective equipment when handling domestic species, and domestic animal aggression can be problematic, sometimes requiring professional behavioural, welfare, and training advice.

Nonetheless, humans still live in close proximity to social canids as well as other domestic species, but the balance of power has tipped toward humans. Through selective breeding, the domestic dog (as an example) has been altered to be distinct genotypically and phenotypically from its ancestors, yet parts of the original genetic information are still there, and the dog is biologically still generally considered to be a subspecies of the wolf. However, it is hypothesized that behaviourally, dogs have been selected and bred for phenotypic behavioural characteristics such as reduced flight distance and increased sociability with humans (Price, 1999). Taking that into consideration, was this early artificial selection made to promote companionship and cooperation, or to increase the degree of control humans can exert?

From competitive sport horses and gun dogs to toy dogs bred for show and as pets; from pedigree cats to the vast array of small animal species kept domestically, domestic companion animals are farmed to meet our needs for sport, utility, status, companionship, and emotional bonding (Spencer et al., 2006). Nonetheless, there is evidence that dogs, at least, form genuine bonds with their human companions (Lewis, 2020b; Nagasawa et al., 2015; Nagasawa et al., 2009) and yet, the common feature for all domestic animals is still, without doubt, the imbalance of power. This can be exemplified in the way humans interact with domestic animals; they are largely infantilized (Lewis, 2020b) and 'conditioned' to meet our demands. Whether it be the 'fear based' training methods commonly employed in training horses (Visser et al., 2009), the aversive techniques previously employed by dog trainers, who believed that dominance by aggression was the most appropriate method of interaction (Haverbeke et al., 2008), or the more recent developments in 'positive reward- based training' (Veeder et al., 2009; Hiby et al., 2004), the premise of human-animal interaction is often not to communicate. The aim is to signal, in simplistic binary terms of 'yes' or 'no', when an individual has met the trainer's requirements. 
Nonetheless, animal training is deemed necessary in society. The premise of positive reward- based training is that it is free of aggression and force, and thus provides for better welfare when training domestic and captive animals, with the assumption that it affords them autonomy and agency. This may be true, to some degree. However, I have previously undertaken postgraduate studies in both 'Clinical Animal Behaviour', and 'Animal Behaviour and Welfare' (respectively) and have fulfilled various occupational roles in animal care and training, including in the equine sector, in dog training, and as an animal care assistant at an animal shelter and on a university small- animal unit. As a result of my experiences, there are two questions I aim to address:

1) Should training be the primary means of interacting with other species?

2) Is 'positive reward- based training' as benign as it is purported to be?

In my attempt to address these questions, I have included some personal anecdotal evidence as examples, having had firsthand experience of both companion animal behaviour and welfare, and the equestrian sector in the UK.

\section{Theoretical Foundations of Animal Training}

Learning theory is originally a behaviourist construct where all behaviour and learning takes place in a stimulus-response based framework, and associative learning occurs via the process of 'reinforcement' and 'punishment' (Young \& Cipreste 2004; Pearce \& Bouton, 2001). The principles used in animal training are based upon the original behaviourists paradigms of conditioning, and are usually presented in a quadratic table. The resulting theory espouses the view that animals make decisions based upon a binary system which either places a positive or negative feedback value on a stimulus, as described in Table 1.

Associative learning is further delineated into either B.F. Skinner's 'operant' (also known as 'instrumental') conditioning i.e., an individual performs a behaviour in order to either obtain a reward or avoid an aversive stimulus (Staddon \& Cerutti 2003); and Ivan Pavlov's 'classical' or 'Pavlovian' conditioning, where an external stimulus, or 'conditioned stimulus' (CS) is associated with an innate physiological response, or 'unconditioned stimulus (US) (Papini \& Bitterman 1990). For example, in Pavlov's famous original experiments, the provision of food created a gustatory response in

Table 1 The premise of learning theory, displayed in the traditional 'quadrat'

$\begin{array}{ll}\begin{array}{l}\text { Positive punishment } \\ \text { - An aversive stimulus is perceived }\end{array} & \begin{array}{c}\text { Negative punishment } \\ \text { - An aversive stimulus is removed } \\ \text { - Behaviour is 'punished' and is less likely to occur } \\ \text { in the future }\end{array} \\ \begin{array}{l}\text { - Behaviour is 'rewarded' and is more likely to occur in } \\ \text { the future }\end{array} \\ \begin{array}{ll}\text { Positive reinforcement } & \text { Negative reinforcement } \\ \text { - A positive stimulus is perceived, which results in } & \text { - A positive stimulus is removed, and a material } \\ \text { material gain/experience of positive affect } & \text { gain/opportunity to experience positive affect is lost } \\ \text { Behaviour is reinforced and is more likely to } & \text { - Behaviour is less likely to occur in the future } \\ \text { occur in the future } & \end{array}\end{array}$


dogs, which was associated with the sound of a ringing bell. Thus, the physiological response is not under conscious control of the organism.

Citing my own experience of being trained in the field of 'clinical animal behaviour', application of these 'conditioning' phenomena involve desired behaviours (such as a 'sit') being 'lured' (i.e., manipulated) or 'captured' (i.e., rewarded on spontaneous occurrence using food titbits). This process is repeated until the behaviour is 'acquired', at which point it is 'put on cue'; jargon for a behavioural response being brought under 'stimulus control'. The difference between 'cue' and a 'command' in this situation is purely euphemistic and moreover, these theories and methods distil behavioural decisions into binomial events, with little or no involvement of perception and complex cognition. Nonetheless, they are used very successfully to train animals, from to domestic ridden horses, sporting dogs and captive raptors, to captive cetaceans at marine wildlife parks, as well as laboratory animals and zoo animals for the purposes of experimentation and handling/husbandry, respectively.

'Positive reward-based' practices rely predominantly on positive and negative reinforcement, with a food reward often being used as the reinforcer (Chiandetti et al., 2016; Gillaspy et al., 2014; Gilis et al., 2012; Mills, 2005). It has even become a mainstream animal management and husbandry strategy, in that animals are being 'rewarded' for performing innate and necessary physiological functions, one example being rewarding dogs with food for excreting faeces and eliminating urine outdoors during house training (Rooney \& Cowan, 2011). Meanwhile, any behaviour which is deemed undesirable is 'ignored', with no social communication, reminiscent of the emotionally unhealthy tactic of 'stonewalling' in human inter-personal relations described by Horan et al., (2015).

Moreover, reward-based training is not simply used for obedience conditioning. Food and other perceived 'rewards' are used to resolve 'problem' behaviours, in cases where animals apparently show a fear response, or even simply a startle response, where the reliance on food as a reward includes associative learning techniques such as 'de-sensitization and counter-conditioning' protocols (Butler et al., 2011). In these examples, food fulfils the role of changing an animal's emotional state from 'negative' to 'positive', or to reduce arousal levels, similar to using a pacifier for a human baby.

Modern behaviour and training concepts do allow for the occurrence of innate behaviours and cognitive processes alongside so-called 'learned' behaviours, as there has been additional input from the field of comparative psychology. Nonetheless, the emphasis is still on giving "commands", as described by Mills (2005). Additionally, animal trainers and behaviourists often attribute instances of undesirable behaviour in companion animals, such as aggression, as being 'learned' phenomena, rather than an innate response to perceived phenomena in the individual's internal or external environment (Horwitz \& Mills, 2009).

Whilst 'positive reward-based trainers' and companion animal behaviourists argue that without the use of force and aversive stimuli, animals have a choice whether to engage with the process, it is difficult to view this as a valid argument. Ultimately, captive animals are being manipulated with the incentive of food, which is a resource integral to their survival. Significantly, as captives, they have no way to escape their trainer, even when the illusion of choice is given. Semiotically, the information which is being conveyed is not one of reward; it is one of 'control of resources' and thus, control of the individual. This interpretation agrees with the findings of Mitchell and 
Edmonson (1999), who found that during play, most of the vocal communications from the owner to their dog were 'controlling', and not "conversational" or "planning". Indeed, so important is the concept of control, that traits such as obedience and trainability are constructs measured in canine personality assessments, such as the 'Monash Canine Personality Questionnaire' (Ley et al., 2009).

Moreover, even if the animal is usually maintained on a healthy, balanced, nutritious diet and the titbits used as 'rewards' are non-essential, we cannot be sure that such complex cognitive processes as understanding that a meal will be provided later in the event a highly desirable treat is rejected, are demonstrated. This is a particularly pertinent point, because studies to date suggest that the personality construct of 'impulsivity' appears to affect an individual's ability to tolerate delayed gratification in dogs (Wright et al., 2012; Riemer et al., 2014). Thus, far from being purely a benign and 'humane' method of communication, if used excessively to 'micro-manage' every aspect of an individual's life, the methods would actually meet the psychological criteria for the phenomenon known as 'coercive control'; a non-violent form of abuse where reward and punishment, close monitoring and threats is used to control a spouse, intimate partner, or family member (Lehmann et al., 2012). The end result is loss of autonomy and agency.

\section{Training as a Form of Communication and Animal Welfare}

In this section, I intend to discuss the application of semiotic theory to human-animal communication. Returning to the example of dogs being 'rewarded' with food to toilet outdoors, it is also the case that animals (particularly dogs) are 'trained' to meet human cultural expectations. These include (but are not limited to) refraining from eating from their food bowl whilst it is placed on the ground, not 'jumping up' at humans when greeted, and even habituating puppies to being handled and socialised using positive and negative rewards. Indeed, examples of such conditioning to human cultural demands can be found in Zulch and Mills 2012 book 'Life Skills for Puppies'. Unarguably, basic training is essential, and using food to promote a positive emotional state or as a distraction can be a useful tool for short term behaviour management, but this should not be at the expense of social learning and developing confidence and emotional resilience using social interaction and communication (Lewis, 2020b). As I will go on to discuss as I progress my argument, these examples of applied training represent an over-reliance on conditioning at the expense of verbal and tactile communication, and social and cultural learning.

Pertinent to my argument is the popularity of the fashionable and lucrative phenomenon, 'clicker training'. An iterative method, animals are trained to perform behaviours using a 'clicker' device, which makes an audible clicking noise when pressed by the trainer. The noise is followed by a food reward and an association is created, making the 'click' a 'reward marker'; thus, it is claimed to 'mark' a discrete behavioral event which is part of a series of successive approximations of the desired behaviour. The training process continues, a bene placito, until the required result is achieved. It allows a behaviour to be gradually 'shaped' without any mutual social interaction or guidance whatsoever, other than 'clicks' followed by food rewards (Feng et al., 2016). The phenomenon has also resulted in the widespread availability of numerous instruction 
books, accessories such as training treat pouches and, of course, the clicker devices themselves. The movement even has its own dedicated annual conferences around the world, called 'ClickerExpo' (Karen Pryor Academy, 2021) aimed at both (and I quote from the website) "enthusiasts and professionals".

Thus, 'clicker training' gives rise to the cultural phenomenon of 'programming' domestic animals using a series of binary input functions, which reduce the trainee to a software program with an appealing and locomotory hardware interface. Whilst I have no doubt that trainers seek to provide the highest welfare standards for their non-human animals, and have genuine affection for them, there is something empty and superficial about individuals being manipulated with meaningless, often unhealthy rewards (such as pieces of chopped-up canned hotdog sausage) for the entertainment or benefit of a powerful 'other' who holds all resources. It is markedly reminiscent of Hendlin's (2019) description of the effects of runaway free- market capitalism, in 'I am a fake loop: the effects of advertising-based artificial selection.' Indeed, in their study on dog training methods, comparing the effectiveness of 'clicker training' to imitation of the human trainer, Fugazza and Miklósi (2015) found what is termed the "Do as I Do" method to be more effective, although it should be noted that this method still involves giving 'commands' and issuing reinforcers at the trainer's discretion. Therefore, it is arguable as to whether this can be classed as true social learning, as is claimed by the authors.

Clicker training is not limited to companion animals, and it is growing in popularity as an animal management strategy in, for example, zoo and laboratory animals (Fernandez \& Dorey, 2020; Leidinger et al., 2017), and in the equine sector, where it is becoming increasingly popular and fashionable to use positive reinforcement to train horses for handling/husbandry purposes, or even just for entertainment. Indeed, there are now many books detailing how to 'clicker train' horses, such as 'Clicker Train Your Horse', by Alexandra Kurland (2007) and 'You Can Train Your Horse to do Anything!' by Shawna Karrasch (2006), along with various websites and social media groups for equine clicker training. Undoubtedly, such methods can be useful as a lessaversive means of ground-schooling (physical conditioning and training of a riderless horse, such as 'loose jumping') and are an alternative to fear-based methods involving lunge-whips and herding. However, the necessity to employ 'stimulus-response' paradigms for general handling and interaction, whilst not completely absent (especially with a species of which individuals who can weigh up to and over $500 \mathrm{~kg}$ ) is limited. It is my personal observation that the equestrian sector is at the stage where canine behaviour and training was approximately two decades ago, when it became increasingly clear that the use of aversive training methods was unacceptable. Neveretheless, in the case of domestic animals such as dogs and horses, if 'positive reward-based training' methods are used as the primary means of communication, they are potentially of no less of concern than traditional methods involving physical force and aggression.

For consideration, also, is the point that there are breed differences (Mehrkam \& Wynne 2014) and individual personality differences (Réale et al., 2010) which must be accounted for when assessing the suitability of reward-based training as a communication tool. For example, whilst pastoral breeds such as the Border Collie often excel in the obedience ring, and are famously conditioned to perform impressive behavioural feats, as described by Pilley and Reid (2011), some breeds of dog such as the Greyhound do not respond to conditioning using reinforcers. Indeed, this characteristic 
is summarized by Hall et al. $(2015, \mathrm{p} .8)$ who, in their report of the results of their odourdiscrimination training session, comment thus:

"Of interest to the authors, nine of the 10 Greyhounds failed to complete the acquisition sessions. The Greyhounds could not be motivated to dig in the bucket of pine shavings, although they would take a treat from the Experimenter".

This result was then commented on by Koskinen et al. (2019, p. 283), who in their discussion of a study relating to medical detection dogs, cited Hall et al. (2015), stated:

“... unsurprisingly, nine out of ten greyhounds failed the training because of a lack of motivation"

Nonetheless, it is my own personal experience, having lived with greyhounds for many years, that these dogs have a high social intelligence, are sensitive and empathic, and have advanced interspecific communicative ability with a strong motivation to form social bonds. Indeed, the importance of recognizing a sign interpreter's capacity to engage semiotically with their environment is summarized by Stables and Gough (2006, p278):

"As with learning, choice can also be understood as simultaneously social and individual — and, thus, as ultimately unpredictable."

Thus, the problem with using the term 'motivation' is that an assumption is made that the dogs have no desire to perform the required behaviour. Instead, the narrative created for the Greyhounds can be re-framed as a breakdown of a sign process, or simply that the dogs disregard signs and signals which to them, have no significant meaning.

Despite these arguments, in some instances it is difficult (if not impossible) to suggest alternatives to training. In cases such as 'recall' training in dogs, where recalling a dog to the handler can be a life-or-death matter; for example, if the dog is heading toward a busy road, conditioning is undoubtedly the safest option to prevent accident and possibly fatal injury of the dog and of road-users. For a dog used in competitive obedience or other sports, training is currently the only viable method available to reach the desired outcome, and the same can be said for equitation. For a ridden horse, pressure from the rider's hands on the reins results in pressure on the bit in the horse's mouth and on the head and face from the bridle (the latter exclusively, in bitless bridle designs). Pressure from the rider's legs on the horse's flanks, and the rider's distribution of weight in the saddle, all act as 'negative punishers', which cause the horse to move, either to terminate an irritating or unpleasant mechanical stimulus, or move in such a way that re-distributes the rider's weight to maintain dynamic equilibrium. Such movements are then 'reinforced' by the rider releasing the pressure (McGreevy \& McLean, 2007).

It is also the case that incentives and rewards are part of reciprocal interactions in social animals, including humans. Indeed, social group formation confers benefits on members, including co-operation during foraging, allo-grooming, and protection 
against predators (Lehmann et al., 2016; Farine et al., 2012). These would broadly meet the definition of 'reinforcers' or 'rewards', yet they are far more complex than a simple binary calculation. Furthermore, the theory of emotional valence, i.e., the 'barometer' by which an animal is believed to measure reward or punishment, postulates that emotional states are generally either positive or negative (Mendl et al., 2010). However, this is an over-simplification. More probable is the occurrence of more than one emotional state at once, creating a phenomenon which can be represented a series of constructs in a complex, multidimensional space. Indeed, it is not only emotions which are likely more complex than is currently understood. Animal communication is multimodal and can involve complex patterns of signals; the definition commonly found in behavioural ecology texts generally defines communication as the 'transfer of energy or matter from one individual to the receiver, which then alters the behaviour of the receiver' (Bradbury \& Vehrencamp, 2011), whilst Martinelli's (2010) zoosemiotic classification of communication places it as being a derivative and relatively small class of semiosis. Training can therefore be classed as a form of communication (and thus, semiosis), albeit a basic, binary form, which manipulates the occurrence of behaviour, rather than prompting a truly autonomous response. Whilst communication uses matter or energy as the conduit, it is information that is transferred, and the receiver (or, more accurately, the 'interpreter') gives that information meaning. Indeed, it is the latter fundamental aspect which widens the definition considerably to potentially encompass all social signals, the salient point being the ability of individuals to perceive and interpret complex, multidimensional patterned signals- or semiosis (Lewis, 2021a,b).

Thus, the meaning of any signal can be uniquely developed between animals and their human caregivers; the issue, however, is compliance. To gain a high degree of compliance i.e., for an animal to perform precise behavioural events and states on command, training via conditioning is necessary. Yet for issues such as toilet training and cultural 'etiquettes' such as dogs not 'jumping up' at people, and horses standing calmly for veterinary examination, patient human verbal and non-verbal communication is sufficient to kindly convey simple meanings, via social learning. As far as negative reinforcement is concerned, the advice given by trainers, to simply 'ignore' unwanted behaviours, is questionable, as this is a tactic used in human passiveaggressive behaviour and does not promote trusting and respectful social relations. There is no evidence that ostracization and refusing to communicate until compliance is achieved is preferable to actively indicating that a behaviour is unacceptable, nor even to showing negative emotion or displeasure, providing the interactions do not constitute abusive or detrimental behaviours, either with respect intensity or frequency.

Whilst my argument recognizes that for animals to live in a domestic or captive environment, some degree of training is necessary, the behaviourist 'learning theory' based paradigm is only the tip of the iceberg with respect their cognitive abilities. For example, dogs have been shown to have empathy (Custance \& Mayer 2012) and are able to read human facial expression (Müller et al., 2015) as well as follow human referential gestures (Hare \& Tomasello, 2005; Soproni et al., 2002), and perform referential gestures for humans (Worsley \& O'Hara, 2018). Significantly, semantic meaning has been attributed to some horse vocalizations (Alberghina et al., 2016), whilst some agricultural species such as goats, which have been domesticated for production (not companion) purposes, have also been found to have the ability to read 
human facial expressions (Nawroth et al., 2018). Further, in wild animals, the vocalizations of some bird species have been found to contain information as to the identity of the signaler (Couchoux \& Dabelsteen, 2015; Ręk \& Osiejuk, 2011), and a simple binary cognitive model based upon reinforcement and prohibition does not fully account for these phenomena, which may well be emergent properties of more basic neurological 'reward' system, but a complex one which is acting dynamically and synergistically (Lewis, 2021a).

Signaling and communication may rely on patterned signals being perceived by one of more interpreters (Lewis, 2020a), but all species sense and perceive the world differently. For example, some bird and insect species perceive light in the ultraviolet part of the spectrum, while many species including bats and other rodents can detect sound waves that are not detectable to the human ear (Heffner \& Heffner, 2008). Numerous mammal species have sensitive vibrissae that can perceive touch (Ahl, 1986), and teleost fish have a lateral line system which allows individuals to perceive changes in water pressure (Hastings et al., 1996). This is only a small example of the spectrum of sensory capabilities which have evolved in living organisms, and the relevance to communication is significant, because of the numerous possible modalities via which communication can occur. For example, a dog has a highly developed olfactory sense. As a form of signaling, dogs can obtain information about another individual, including sex, age, and reproductive status, from its scent (Cafazzo et al., 2012). It is therefore pertinent that all efforts to detect linguistic features such as grammar and syntax in animal communications have misguidedly focused on vocalization and ignored other modalities. This seems shortsighted when in humans, sign language is considered a language in its own right. (Clay et al., 2014; Cooper et al., 2011). Thus, the possibility that grammar and syntax can be present in, for example, sequences of odour molecules (or indeed via any other sensory modality) is an avenue worth exploring (Lewis, 2021a). Indeed, artificial pheromone analogues are used in the behavioural management of companion animals, the aim being to promote a sense of calm and safety (Tod et al., 2005). Whilst the research and development data as to how these pheromones were isolated is not available publicly, it does demonstrate that our searches for language capabilities in other species may be very short-sighted. It is entirely possible that the olfactory schema and mental map (Gómez, 2019) of a dog gives rise to a form of 'language', where the grammar, syntax, the ability to communicate intention, and express abstract ideas may well be present, but in an olfactory form. Thus, complex patterned signals are very much part of a dog's Umwelt and semiosphere (Lewis, 2021b). If an animal is therefore capable of interpreting the meanings of kinesic, auditory, visual, chemical, and tactile signs and signals, then to limit their lexicon to a binary 'yes' or 'no', or 'reward' and 'punishment' is injudicious. Indeed, it ought to be considered that there may be welfare implications in placing such extensive restrictions on an individual's 'vocabulary' when we do not know the full extent of their capabilities.

Despite this, whilst it is now generally accepted that companion animals are sentient and have complex cognitive abilities, one of the arguments commonly used to promote behaviourist training methods is the theory of 'contra-freeloading'. This is the theory that animals will perform 'work' (such as lever-pressing) to obtain food, even when an alternative food source is freely available (da Silva Vasconcellos et al., 2012). This phenomenon has apparently been observed in a variety of domestic species, including 
cattle (Van Os et al., 2018) and goats (Rosenberger et al. 2020), as well as the captive wolves in da Silva Vasoncellos et al.'s (2012) study. Indeed, such findings have even driven the development of food puzzle toys used for 'environmental enrichment' for captive and domestic animals (Dantas et al., 2016). However, one consistent argument against the theory of contra-freeloading is the 'optimal foraging theory model', which predicts that animals maximize their energy intake, as demonstrated by Zach's (1979) well-known study on shell-dropping in crows feeding on molluscs. Indeed, Young and Lauren (2003) found no convincing evidence for contra-freeloading in pigs, and Podlesnik and Gomez (2016) suggest the phenomenon is the result of complex behavioural processes, and not simply an innate desire to 'work' for food. Examples of such behavioural processes include gaining information about a patchy habitat, when foraging on patches where resources are limited (Mason, 1999) and the 'behavioural momentum' theory (Podlesnik \& Gomez, 2016) where animals are thought to persist to 'work' to obtain food because the behaviour itself has been 'rewarded' previously. Indeed, the latter explanation is actually supported by Rosenberger et al. (2020), who found that the goats in their study increased their preference for the 'contra-freeloading' option in the second experimental trial, suggesting the first trial had led to a conditioned response. It is therefore likely that even during the first trial, the animals used as experimental subjects were not naïve to conditioning paradigms or husbandry strategies employing conditioning techniques. Thus, whilst I have personally heard many dog trainers and behaviourists claim that dogs are being "paid" to work, and that behaviour practitioners can even have "credit in the bank" in the event mistakes are made by the trainer, such contradictions and alternative explanations call into question what is in effect the application of a capitalist political and socio-economic model to non-human animals.

Indeed, the work of Filip Jaroš, focusing on domestic and feral cats, demonstrates how the application of semiotic theory changes our perception and understanding of animal behaviour. For example, Jaroš (2017) describes a semiotic study on a group of feral domestic cats, which gives a very different result to the traditional view that cats are evolutionarily solitary, asocial animals, and this view, as a result, would typically suit them more to a 'clicker' style training method as opposed social signaling. However, moving away from Neo-Darwinist, 'Natural Selection' concepts, it is revealed that cats interact cooperatively and socially via shared signs in a Total Umwelt and the associated semiosphere. Thus, this study demonstrates how semiosis can provide a means by which we can interpret and study animal behaviour, and, significantly, the potential possibilities of how we can communicate with animals using signs and signals.

\section{What are the Alternative Cognitive Theories to Behaviorist 'Learning Theory' which Support these Ideas?}

Whilst it would be impossible to dismiss simple binary calculations as being irrelevant, current enactivist theories of cognition are based upon probability algorithms, such as Bayes' Theorem, as well as the minimization of sums of error. This means organisms find the 'least' wrong solution, rather than the 'right' solution (Kirchhoff \& Robertson, 2018; Kukkoken, 2016). An example can be seen in 'gradient descent searches'; a 
foraging strategy whereby an organism repeatedly samples the environment to find the fastest rate of net gain of a resource, by using iterative exploratory processes (Dasgupta et al., 2009; Meuleau \& Dorigo, 2002). The premise is that rather than using immediate reward and/or punishment, cognitive processes work on a multitude of predictive outcomes which form complex patterns. The associated sign-process is not based upon the reductionist 'stimulus-response' or 'reward' or 'no-reward', but on the embodied response of the organism to its environment, which gives rise to a more 'approach' and avoid' style system, that can account for net effects and agency. To summarize, a probabilistic calculation of the best solution to a problem is made (i.e., the 'reward'), but confounding factors such as the relative quality of an exploitable resource, necessary energy expenditure, the risk of threat from predators, social bonds/ altruism/ reciprocity, and other environmental factors, are also taken into account. In essence, the individual has agency and autonomy and can even choose to make apparently 'poor' logical decisions (resulting in loss or net harm), for emotional reasons. Such is the nature of apparently biologically pointless phenomena like 'aesthetic appreciation'.

Furthermore, emotions are viewed as an enmeshed part of the cognitive process, with emotional inputs acting as factors which alter cognitive functions. Therefore, rather than being a simple logic algorithm, multiple factors are involved in cognition. This allows not only for the processing of data in binary terms, but also allows for the processing of large and varied amounts of sensory data and complex cognitive functions (Damasio, 2004). Thus, the semiotic scaffolding (Kull, 2015; Hoffmeyer, 2014b) in which an organism exists, and with which it can exploit its environment and semiosphere is present. These abilities develop and evolve not just during the ontogenetic period, but throughout the organism's whole life.

As animal communications have semantic meaning, born from complex patterned signals, there is no reason why animals such as dogs may not decode the basic meaning of human vocalizations, even if only by the simple process of analyzing the acoustic parameters of each sound. These sound patterns can then be memorized, recognized, and placed in context, particularly when repetition is involved. Certainly, if dogs can read the emotional valence of human facial expressions, then decoding the basic semantics of human language should be possible. For example, a basic intention, referential sounds or gestures, expression of emotion, or even nouns are within these animals' semiotic capability. Significantly, the studies which test human capability to perceive meaning in animal vocalizations (particularly dog vocalizations) give positive results (Pongrácz et al., 2006), indicating that even inexperienced humans who have had little contact with dogs instinctively interpret the vocal signals produced by dogs. Surely, therefore, it is not too big a leap to assume the converse can be true.

Whilst studies must eliminate the possibility of a conditioned response being the underlying factor in apparent cases of animals 'understanding' more complex concepts and making word associations, it is a valid logical argument that for the Umwelten of two species to meet and form a semiosphere, a fundamental mutual understanding must be present. This gives rise to a more constructivist approach to animal learning (Yager, 1991), rather than the simple 'reward and punishment' paradigm so commonly employed in human-animal interactions. Further, this hypothesis applies to situations where the owner is absent. For example, building trust, a sense of safety, confidence, and emotional resilience can be key in dealing with problems such as perceived 'separation issues', which are highly socially and psychologically complex (Lewis, 
2020b) yet are often addressed using paradigms which place an emphasis on food reinforcers (Butler et al., 2011), or pacifiers. In looking beyond simple conditioning and B.F Skinner's 'reinforcement' and 'punishment', and introducing Peirce's 'Firstness, Secondness and Thirdness' (Semetsky, 2005) to explain apparent 'instrumental conditioning', the possibilities of reaching beyond the simple mechanistic behaviourist learning theory become apparent. It then becomes possible to acknowledge meaningful interactions between humans and alloanimals, and alloanimals and their wider environment.

\section{Conclusion}

Whilst undeniably, basic training using lures and rewards is necessary, the focus on 'positive reward-based' training paradigms when interacting with domestic animal species gives little, if any, room for more complex communication or signaling to take place. Moreover, they reduce individuals of other species to little more than automata, responding to binary inputs. In these circumstances, how can the animal's human companion, or the animals themselves, achieve a true bond and interspecific relationship? The most logically unsound argument commonly proposed to support these paradigms is that because physical force is not used, they are 'humane' and 'kinder'. However, the comparisons with coercive control and psychological manipulation are striking. A more innate, complex, and dynamic interspecific means of communication should not be supplanted by repetitive conditioning and 'commands', which are fast becoming a widespread misapplication of a genuine, but misunderstood and overutilized, biological principle. Nor is it possible to quantify and 'proscribe' communication, as though it were a simple recipe which can be reduced to pre-determined steps. Thus, positive reward- based training has a place as a technique in animal management, but it is not without risks, and it should be understood as what it is; manipulation and coercion (with threat of loss of resources or social interaction) focused on maintaining control. Substantive arguments that as a training technique, it is preferable to fearbased methods and physically aggressive practices, do not alter this statement. As a means of communication, it should not be relied upon as the primary modality, and consideration should be given to more appropriate interactions alongside methods such as 'clicker training', which should not be used without vocal or tactile communication and guidance from the trainer, as described by Fugazza and Miklósi (2015).

Perhaps, in moving away from 'The Five Freedoms' model of animal welfare, toward a quality-of-life based assessment scale which emphasizes positive welfare rather than the absence of poor welfare (Mellor, 2016), we should begin to change our thinking about how we interact and communicate with domestic and captive animals. This may ultimately lead toward an acceptance that training is not the most enlightened way of communicating with other species, alongside an accompanying paradigm shift toward complex dynamic semiosis, mutual understanding, 'Total Umwelten', and ultimately, a more balanced semiosphere.

Acknowledgements Thank you to my Greyhound, Jemima, and my previous Greyhound, Boo, both of whom are/were highly motivated to form interspecific social-bonds and to communicate with me. 
Thanks also to the anonymous reviewers, who provided valuable insights and guidance, and helped me to structure the manuscript.

\section{Declarations}

Ethical Statement My personal interactions with animals, in the course of gathering of information for this paper, have complied with UK animal welfare and ethical standards. I have not personally been involved in the import/export of live animals.

Conflicts of Interest There are no conflicts of interest to declare.

Open Access This article is licensed under a Creative Commons Attribution 4.0 International License, which permits use, sharing, adaptation, distribution and reproduction in any medium or format, as long as you give appropriate credit to the original author(s) and the source, provide a link to the Creative Commons licence, and indicate if changes were made. The images or other third party material in this article are included in the article's Creative Commons licence, unless indicated otherwise in a credit line to the material. If material is not included in the article's Creative Commons licence and your intended use is not permitted by statutory regulation or exceeds the permitted use, you will need to obtain permission directly from the copyright holder. To view a copy of this licence, visit http://creativecommons.org/licenses/by/4.0/.

\section{References}

Ahl, A. S. (1986). The role of vibrissae in behavior: a status review. Veterinary Research Communications, 10(1), 245-268

Alberghina, D., Caudullo, E., Chan, W. Y., Bandi, N., \& Panzera, M. (2016). Acoustic characteristics of courtship and agonistic vocalizations in Przwewalskii's wild horse and in domestic horse. Applied Animal Behaviour Science, 174, 70-75

Bradbury, J. W., \& Vehrencamp, S. L. (2011). Principles of animal communication (2nd ed.) Sinauer

Butler, R., Sargisson, R. J., \& Elliffe, D. (2011). The efficacy of systematic desensitization for treating the separation-related problem behaviour of domestic dogs. Applied Animal Behaviour Science, 129(2-4), $136-145$

Cafazzo, S., Natoli, E., \& Valsecchi, P. (2012). Scent-marking behaviour in a pack of free-ranging domestic dogs. Ethology, 118(10), 955-966

Chiandetti, C., Avella, S., Fongaro, E., \& Cerri, F. (2016). Can clicker training facilitate conditioning in dogs? Applied Animal Behaviour Science, 184, 109-116

Clay, Z., XXXeople, S., Hood, B., \& Kita, S. (2014). Young children make their gestural communication systems more language-like: Segmentation and linearization of semantic elements in motion events. Psychological Science,25(8), 1518-1525

Cooper, H., Holt, B., \& Bowden, R. (2011). Sign language recognition. In T. B. Moeslund, A. Hilton, V. Krüger, \& L. Sigal (Eds.), Visual Analysis of Humans (pp. 539-562). Springer

Couchoux, C., \& Dabelsteen, T. (2015). Acoustic cues to individual identity in the rattle calls of common blackbirds: a potential for individual recognition through multi-syllabic vocalisations emitted in both territorial and alarm contexts. Behaviour, 152(1), 57-82

Custance, D., \& Mayer, J. (2012). Empathic-like responding by domestic dogs (Canis familiaris) to distress in humans: an exploratory study. Animal Cognition, 15(5), 851-859

Damasio, A. R. (2004). Manstead. In A. S. R. Frijda \& N. Fischer (Eds.), Emotions and Feelings. Cambridge University Press

Dantas, L. M., Delgado, M. M., Johnson, I., \& Buffington, C. T. (2016). Food puzzles for cats: feeding for physical and emotional wellbeing. Journal of Feline Medicine and Surgery, 18(9), 723-732

Dasgupta, S., Das, S., Abraham, A., \& Biswas, A. (2009). Adaptive computational chemotaxis in bacterial foraging optimization: an analysis. IEEE Transactions on Evolutionary Computation,13(4), 919-941

Da Silva Vasconcellos, A., Adania, C. H., \& Ades, C. (2012). Contrafreeloading in maned wolves: Implications for their management and welfare.Applied Animal Behaviour Science,140(1-2), 85-91 
Farine, D. R., Garroway, C. J., Ben, C., \& Sheldon, B. C. (2012). Social network analysis of mixed-species flocks: exploring the structure and evolution of interspecific social behaviour. Animal Behaviour,84, 1271-1277

Feng, L. C., Howell, T. J., \& Bennett, P. C. (2016). How clicker training works: comparing reinforcing, marking, and bridging hypotheses. Applied Animal Behaviour Science, 181, 34-40

Fernandez, E. J., \& Dorey, N. R. (2020). An examination of shaping with an African Crested Porcupine (Hystrix cristata). Journal of Applied Animal Welfare Science, 1-7

Fugazza, C., \& Miklósi, Ã. (2015). Social learning in dog training: The effectiveness of the Do as I do method compared to shaping/clicker training. Applied Animal Behaviour Science,171, 146-151

Gillaspy, J. A., Jr, Brinegar, J. L., \& Bailey, R. E. (2014). Operant psychology makes a splash-in marine mammal training (1955-1965). Journal of the History of the Behavioral Sciences, 50(3), 231-248

Gillis, T. E., Janes, A. C., \& Kaufman, M. J. (2012). Positive reinforcement training in squirrel monkeys using clicker training. American Journal of Primatology, 74(8), 712-720

Gómez, S. R. (2019). Cartographies of the mind: Generalization and relevance in cognitive landscapes. Sign Systems Studies, 47(3/4), 382-399

Hall, N. J., Glenn, K., Smith, D. W., \& Wynne, C. D. (2015). Performance of Pugs, German Shepherds, and Greyhounds (Canis lupus familiaris) on an odor-discrimination task. Journal of Comparative Psychology, 129(3), 237

Hare, B., \& Tomasello, M. (2005). Human-like social skills in dogs? Trends in Cognitive Sciences, 9(9), 439444

Hastings, M. C., Popper, A. N., Finneran, J. J., \& Lanford, P. J. (1996). Effects of low-frequency underwater sound on hair cells of the inner ear and lateral line of the teleost fish Astronotus ocellatus. The Journal of the Acoustical Society of America, 99(3), 1759-1766

Haverbeke, A., Laporte, B., Depiereux, E., Giffroy, J. M., \& Diederich, C. (2008). Training methods of military dog handlers and their effects on the team's performances. Applied Animal Behaviour Science, $113(1-3), 110-122$

Heffner, H. E., \& Heffner, R. S. (2008). High-frequency hearing. Handbook of the senses: Audition, 55, 60

Hendlin, Y. H. (2019). I am a fake loop: the effects of advertising-based artificial selection. Biosemiotics, 12(1), 131-156

Hiby, E. F., Rooney, N. J., \& Bradshaw, J. W. S. (2004). Dog training methods: their use, effectiveness and interaction with behaviour and welfare. Animal Welfare-Potters Bar then Wheathampstead, 13(1), 63-70

Hoffmeyer, J. (2014a). The semiome: From genetic to semiotic scaffolding. Semiotica, 2014(198), 11-31

Hoffmeyer, J. (2014b). Semiotic scaffolding: A biosemiotic link between sema and soma. In K. R. Cabell \& J. Valsiner (Eds.), The catalyzing mind: Beyond models of causality (pp. 95-110). Springer

Horan, S. M., Guinn, T. D., \& Banghart, S. (2015). Understanding relationships among the dark triad personality profile and romantic partners' conflict communication. Communication Quarterly, 63(2), $156-170$

Horwitz, D., \& Mills, D. (2009). BSAVA manual of canine and feline behavioural medicine. British Small Animal Veterinary Association

Jaroš, F. (2017). The Three Semiotic Lives of Domestic Cats: A Case Study on Animal Social Cognition. Biosemiotics, 10(2), 279-293.Karrasch, S. (2006). You can train your horse to do anything! On target training: clicker training and beyond. Quiller Publishing Ltd.

Kirchhoff, M. D., \& Robertson, I. (2018). Enactivism and predictive processing: a non-representational view. Philosophical Explorations, 21(2), 264-281

Koskinen, A., Bachour, A., Vaarno, J., Koskinen, H., Rantanen, S., Bäck, L., \& Klockars, T. (2019). A detection dog for obstructive sleep apnea. Sleep and Breathing, 23(1), 281-285

Kukkonen, K. (2016). Bayesian bodies: The predictive dimension of embodied cognition and culture. In Garrett, P. (Ed.) The Cognitive Humanities (pp. 153-167). Palgrave Macmillan

Kull, K. (2015). Evolution, choice, and scaffolding: Semiosis is changing its own building. Biosemiotics, 8(2), 223-234

Kurland, A. (2007). Clicker training for your horse. Ringpress Books

Lehmann, J., Majolo, B., \& McFarland, R. (2016). The effects of social network position on the survival of wild Barbary macaques, Macaca sylvanus. Behavioral Ecology, 27, 20-28

Lehmann, P., Simmons, C. A., \& Pillai, V. K. (2012). The validation of the checklist of controlling behaviors (CCB) assessing coercive control in abusive relationships. Violence Against Women, 18(8), 913-933

Leidinger, C., Herrmann, F., Thöne-Reineke, C., Baumgart, N., \& Baumgart, J. (2017). Introducing clicker training as a cognitive enrichment for laboratory mice. Journal of visualized experiments: JoVE, (121)

Lewis, A. (2021a). Chemiosemiosis and complex patterned signals: A chemosemiotic hypothesis of language evolution. Linguistic Frontiers, 4(1), 10-24 
Lewis, A. (2021). A semiotic modern synthesis: Conducting quantitative studies in zoosemiotics and interpreting existing ethological studies through a semiotic framework. Biosemiotics, 1-33

Lewis, A. (2020a). Total umwelten create shared meaning the emergent properties of animal groups as a result of social signalling. Biosemiotics, 13(3), 431-441

Lewis, A. (2020b). Infantilizing companion animals through attachment theory: why shift to behavioral ecology-based paradigms for welfare. Society \& Animals, 1(aop), 1-18

Ley, J. M., Bennett, P. C., \& Coleman, G. J. (2009). A refinement and validation of the Monash Canine Personality Questionnaire (MCPQ). Applied Animal Behaviour Science, 116(2-4), 220-227

Martinelli, D. (2010). A critical companion to Zoosemiotics: people, paths, ideas (Vol. 5 ). Springer Science \& Business Media

Mason, G. J. (1999). Contrafreeloading in starlings: testing the information hypothesis. Behaviour, 136(1011), 1267-1282

McGreevy, P. D., \& McLean, A. N. (2007). Roles of learning theory and ethology in equitation. Journal of Veterinary Behavior, 2(4), 108-118

Mellor, D. (2016). Updating animal welfare thinking: Moving beyond the "Five Freedoms" towards "a Life Worth Living". Animals, 6(3), 21

Mendl, M., Burman, O. H., \& Paul, E. S. (2010). An integrative and functional framework for the study of animal emotion and mood. Proceedings of the Royal Society B: Biological Sciences, 277(1696), 28952904

Mehrkam, L. R., \& Wynne, C. D. (2014). Behavioral differences among breeds of domestic dogs (Canis lupus familiaris): Current status of the science. Applied Animal Behaviour Science, 155, 12-27

Meuleau, N., \& Dorigo, M. (2002). Ant colony optimization and stochastic gradient descent. Artificial life, $8(2), 103-121$

Mills, D. S. (2005). What's in a word? A review of the attributes of a command affecting the performance of pet dogs. Anthrozoös, 18(3),208-221

Mitchell, R. W., \& Edmonson, E. (1999). Functions of repetitive talk to dogs during play: Control, conversation, or planning? Society \& Animals, 7(1), 55-81

Morey, D. F. (1994). The early evolution of the domestic dog. American Scientist, 82(4), 336-347

Müller, C. A., Schmitt, K., Barber, A. L., \& Huber, L. (2015). Dogs can discriminate emotional expressions of human faces. Current Biology, 25(5), 601-605

Nagasawa, M., Mogi, K., \& Kikusui, T. (2009). Attachment between humans and dogs. Japanese Psychological Research, 51(3), 209-221

Nagasawa, M., Mitsui, S., En, S., Ohtani, N., Ohta, M., Sakuma, Y., \& Kikusui, T. (2015). Oxytocin-gaze positive loop and the coevolution of human-dog bonds. Science, 348(6232), 333-336

Nawroth, C., Albuquerque, N., Savalli, C., Single, M. S., \& McElligott, A. G. (2018). Goats prefer positive human emotional facial expressions. Royal Society Open Science, 5(8), 180491

Papini, M. R., \& Bitterman, M. E. (1990). The role of contingency in classical conditioning. Psychological Review, 97(3), 396

Pearce, J. M., \& Bouton, M. E. (2001). Theories of associative learning in animals. Annual Review of Psychology, 52(1), 111-139

Pilley, J. W., \& Reid, A. K. (2011). Border collie comprehends object names as verbal referents. Behavioural Processes, 86(2), 184-195

Podlesnik, C. A., \& Jimenez-Gomez, C. (2016). Contrafreeloading, reinforcement rate, and behavioral momentum. Behavioural Processes, 128, 24-28

Pongrácz, P., Molnár, C., \& Miklósi, Ã. (2006). Acoustic parameters of dog barks carry emotional information for humans. Applied Animal Behaviour Science, 100(3-4), 228-240

Price, E. O. (1999). Behavioral development in animals undergoing domestication. Applied Animal Behaviour Science, 65(3), 245-271

Réale, D., Dingemanse, N. J., Kazem, A. J., \& Wright, J. (2010). Evolutionary and ecological approaches to the study of personality. Philosophical Transactions of the Royal Society B: Biological Sciences, 365(1560), 3937-3946

Riemer, S., Mills, D. S., \& Wright, H. (2014). Impulsive for life? The nature of long-term impulsivity in domestic dogs. Animal Cognition, 17(3), 815-819

Ręk, P., \& Osiejuk, T. S. (2011). No male identity information loss during call propagation through dense vegetation: the case of the corncrake. Behavioural Processes, 86(3), 323-328

Rooney, N. J., \& Cowan, S. (2011). Training methods and owner-dog interactions: Links with dog behaviour and learning ability. Applied Animal Behaviour Science, 132(3-4), 169-177

Rosenberger, K., Simmler, M., Nawroth, C., Langbein, J., \& Keil, N. (2020). Goats work for food in a contrafreeloading task. Scientific reports, 10(1), 1-12 
Zach, R. (1979). Shell dropping: decision-making and optimal foraging in northwestern crows. Behaviour, 106-117

Semetsky, I. (2005). Peirce and education: An introduction. Educational Philosophy and Theory, 37(2), 153156

Soproni, K., Miklósi, Ã, Topál, J., \& Csányi, V. (2002). Dogs'(Canis familaris) responsiveness to human pointing gestures. Journal of comparative psychology, 116(1), 27

Spencer, S., Decuypere, E., Aerts, S., \& De Tavernier, J. (2006). History and ethics of keeping pets: Comparison with farm animals. Journal of Agricultural and Environmental Ethics, 19(1), 17-25

Staddon, J. E., \& Cerutti, D. T. (2003). Operant conditioning. Annual review of psychology, 54(1), 115-144

Stables, A., \& Gough, S. (2006). Toward a semiotic theory of choice and of learning. Educational Theory, 56(3), 271-285

Tod, E., Brander, D., \& Waran, N. (2005). Efficacy of dog appeasing pheromone in reducing stress and fear related behaviour in shelter dogs. Applied Animal Behaviour Science, 93(3-4), 295-308

Van Os, J. M., Mintline, E. M., DeVries, T. J., \& Tucker, C. B. (2018). Domestic cattle (Bos taurus taurus) are motivated to obtain forage and demonstrate contrafreeloading. PLoS One, 13(3), e0193109

Veeder, C. L., Bloomsmith, M. A., McMillan, J. L., Perlman, J. E., \& Martin, A. L. (2009). Positive reinforcement training to enhance the voluntary movement of group-housed sooty mangabeys (Cercocebus atys atys). Journal of the American Association for Laboratory Animal Science,48(2), 192-195

Vilà, C., Maldonado, J. E., \& Wayne, R. K. (1999). Phylogenetic relationships, evolution, and genetic diversity of the domestic dog. Journal of Heredity, 90(1), 71-77

Visser, E. K., VanDierendonck, M., Ellis, A. D., Rijksen, C., \& Van Reenen, C. G. (2009). A comparison of sympathetic and conventional training methods on responses to initial horse training. The Veterinary Journal, 181(1), 48-52

Worsley, H. K., \& O’Hara, S. J. (2018). Cross-species referential signalling events in domestic dogs (Canis familiaris). Animal Cognition, 21(4), 457-465

Wright, H. F., Mills, D. S., \& Pollux, P. M. (2012). Behavioural and physiological correlates of impulsivity in the domestic dog (Canis familiaris). Physiology \& Behavior, 105(3), 676-682

Yager, R. E. (1991). The constructivist learning model. The Science Teacher, 58(6), 52

Young, R. J., \& Cipreste, C. F. (2004). Applying animal learning theory: training captive animals to comply with veterinary and husbandry procedures. Animal Welfare, 13(2), 225-232

Young, R. J., \& Lawrence, A. B. (2003). Do domestic pigs in controlled environments contrafreeload?. Journal of Applied Animal Welfare Science, 6(4), 309-318

Zulch, H., \& Mills, D. (2012). Life skills for puppies. Veloce Publishing Ltd

\section{Websites}

ClickerExpo, The Karen Pryor Academy. (2021). https://clickerexpo.clickertraining.com/. Accessed Mar 2021

Publisher's Note Springer Nature remains neutral with regard to jurisdictional claims in published maps and institutional affiliations. 